\title{
A nicotinic hypothesis for Covid-19 with preventive and therapeutic implications
}

\author{
jean-pierre CHANGEUX, Zahir Amoura ${ }^{1}$, Felix Rey², Makoto Miyara \\ 1 Assistance Publique - Hôpitaux de Paris \\ 2 Pasteur Institute
}

\begin{abstract}
SARS-CoV-2 epidemics raises a considerable issue of public health at the planetary scale. There is a pressing urgency to find treatments based upon currently available scientific knowledge. Therefore, we tentatively propose a hypothesis which hopefully might ultimately help saving lives. Based on the current scientific literature and on new epidemiological data which reveal that current smoking status appears to be a protective factor against the infection by SARS-CoV-2 [1], we hypothesize that the nicotinic acetylcholine receptor (nAChR) plays a key role in the pathophysiology of Covid-19 infection and might represent a target for the prevention and control of Covid-19 infection.
\end{abstract}

Symptomatic Covid-19 disease (as caused by SARS-CoV-2 virus) is observed in 2.5 percent of infected individuals [2] indicating an individual variability in the clinical presentation. Among the epidemiological and clinical features of Covid-19, the following features are of special interest for understanding the patho-physiolology, namely: (1) in outpatients with favorable outcome : neurological/psychiatric disorders, especially loss of sense of smell which is specific of the disease and (2) in hospitalized older patients with a poor prognosis : systemic hyperinflammatory syndrome with increased levels of circulating cytokines and atypical acute respiratory distress syndrome with loss of neurological control of lung perfusion regulation and hypoxic vasoconstriction [3]. This raises the issue of the basis of inter-individual variability for the susceptibility to infection.

The nAChR appears as a hypothetical clue for the main clinical manifestations of Covid19. It is accepted that the angiotensin converting enzyme 2 (ACE2), represents the principal receptor molecule for SARS-CoV-2 [4-6]. ACE2 is expressed at the transcriptomic level in the lung, the small intestine and colon, in the kidney, in the testis, in the heart muscle and in the brain, yet the protein is not detected in the lung [7]. In the brain, ACE2 is expressed in both neurons and glia and particularly present in the brain 
stem and in the regions responsible for the regulation of cardiovascular functions, including the subfornical organ, paraventricular nucleus, nucleus of the tractus solitarius, and rostral ventrolateral medulla [8]. Additional receptors or co-receptors are, however, not excluded. The relationship between nicotine and ACE2 has been explored in the framework of cardiovascular and pulmonary diseases [9]. Accordingly, in the ACE/ANG II/AT 1R arm, nicotine increases the expression and/or activity of renin, ACE and AT 1R, whereas in the compensatory ACE2/ANG-(1-7)/MasR arm, nicotine down regulates the expression and/or activity of ACE2 and AT2R, thus suggesting a possible contribution of acetylcholine receptors in ACE2 regulation. This possibility has not yet been explored in the framework of viral neuroinfections.

There is strong evidence for a neurotropic action of SARS-CoV-2 infection. It has been demonstrated that $\beta$-coronaviruses to which the SARS- CoV-2 belongs, do not limit their presence to the respiratory tract and have been shown to frequently invade the CNS [10] . This propensity has been convincingly documented for the SARS-CoV-1, MERS-CoV and the coronavirus responsible for porcine hemagglutinating encephalomyelitis (HEV 67N). In light of the high similarity between SARS-CoV-1 and SARS-CoV-2, it is quite likely that SARS-CoV-2 also possesses a similar potential. Neuroinfection has been proposed to potentially contribute to the pathophysiology and clinical manifestations of Covid-19 [10] with the neuroinvasive potential of SARS-CoV-2 suggested to play a role in the respiratory failure of Covid-19 patients [11, 12]. Our nicotinic hypothesis proposes that the virus could enter the body through neurons of the olfactory system and/or through the lung leading to different clinical features with different outcome, and contrasts with the currently accepted view that ACE2 is the principal receptor of SARS-CoV-2 for its entry into cells.

As mentioned, loss of sense of smell frequently occurs in Covid-19 patients [13]. Furthermore, several studies have reported that some patients infected with SARS-CoV-2 show neurologic signs such as headache (about 8\%), nausea and vomiting (1\%) [11]. More recently, a study of 214 Covid-19 patients [14] further found that about $88 \%$ (78/88) of the severe patients displayed neurologic manifestations including acute cerebrovascular diseases and impaired consciousness. Based on an epidemiological survey on Covid-19, the median time from the first symptom to dyspnea was 5.0 days, to hospital admission was 7.0 days, and to the intensive care was 8.0 days [15]. Therefore, the latency period may be adequate for the virus to enter the nervous system, invade the brain stem and affect the medullary neurons of the respiratory centers. However, variability of the neurological signs was observed with patients having anosmia, showing in general a mild evolution without pulmonary attack, in contrast with those without anosmia suggesting a diversity in the mode of proliferation and /or progression of the 
virus.

More than 20 years ago, Mohammed, Norrby \& Kristensson [16], in a pioneering study, showed with a broad diversity of viruses (Poliovirus, Herpes simplex virus, West Nile virus , Vesicular Stomatitis Virus, influenza H1N1 virus [17]), that viruses enter the olfactory epithelium and progress first through the olfactory pathway in an anterograde direction and then in a retrograde manner to the reticular neurons projecting to the olfactory bulbs, the median raphe neurons (serotoninergic) and the ventral and horizontal diagonal band (cholinergic) $[16,18]$. This olfactory infection route scheme [18] has been recently extended to Covid-19 infection $[2,11]$. T o further investigate the molecular aspects of Covid-19 propagation in the brain and its pharmacology, we have been aided by abundant studies on rabies virus (RABV) a negative polarity, single-strand RNA virus that is distinct from the coronaviruses [18-20]. nAChRs were shown to be the first receptors for RABV [21]. Structural studies further revealed that a short region in the ectodomain of the rabies virus glycoprotein shows sequence similarity to some snake toxins $[20,22]$ that were initially used to isolate the nAChR from fish electric organs [23]). These snake toxins [24] are known to bind with high affinity and exquisite selectivity to the peripheral muscle receptor, while also to some brain receptors $[25,26]$. The neurotoxin-like region of the rabies virus glycoprotein inhibited acetylcholine responses of $\alpha 4 \beta 2 n A C h R s$ in vitro, as did the full length ectodomain of the rabies virus glycoprotein [20]. The same peptides significantly altered a nAChR elicited behaviour in C. elegans and increased locomotor activity levels when injected into the CNS of mice [20]. The nAChR thus plays a critical role in the host-pathogen interaction in the case of the RABV. Furthermore, a broad variety of nAChR olig omers are distributed throug hout the brain, including the reticular core neurons and the spinal cord, with the $\square 402$ and 7 nAChR oligomers being the most frequent [27]. The hypothesis we wish to explore is to what implications these data may hold for SARS-CoV-2 infection and we suggest a strong role of nAChR in the disorder. The nAChR pathway is hypothesized to be engaged in the Covid-19 inflammatory syndrome. The nervous system, through the vagus nerve, can significantly and rapidly inhibit the release of macrophage TNF, and attenuate systemic inflammatory responses [28]). This physiological mechanism, termed the 'cholinergic anti-inflammatory pathway' has major implications in immunology and in therapeutics. The cytokine production of macrophages - one of the main cell types found in the bronchoalveolar fluid - is under the physiological control of auto/paracrine acetylcholine through their nAChRs [29]. Following dysregulation of macrophage nAChRs, the profile of cytokines massively secreted include II1, II6, TNF et II18. This cytokine profile shows striking analogies with the cytokine storm syndrome, leading to the hyperinflammatory syndrome described in a subgroup of Covid-19 patients [30]; Systemic coagulopathy with venous and arterial 
thrombosis is one of the critical aspects of the morbidity and mortality of Covid-19. In line with our hypothesis, one should note that hematopoietic $\mathrm{Q7-nAChR}$ deficiency increases platelet reactive status, which could explain the thrombogenic presentation of Covid-19 [31].

Although selective cytokine blockers (eg, IL1-receptor antagonist anakinra or anti-IL6 tocilizumab) have been proposed for the control of Covid-19 cytokine storm, their efficacy is still to be explored. Interestingly, $૧ 7$ agonists, including nicotine, have proven to be effective in reducing macrophage cytokine production and inflammation in animal models of pancreatitis [32] and peritonitis [33]. In this setting, a nicotinic treatment that might possibly antagonize the blocking action of SARS-CoV-2 on the AChR through a possible modulation of the ACE2 - nAChR interaction, would act earlier than anti-cytokine therapies. nAChR modulation by Covid-19 might tentatively account for the hyperinflammatory features observed in a subgroup of Covid-19 patients, mimicking bona fide the macrophage activation syndrome.

Of note, our hypothesis could explain the high prevalence of obesity and diabetes mellitus observed in severe forms of Covid19. The diminished vagus nerve activity previously described in these two illnesses could be potentiated by the Covid-19 elicited nicotinic receptor dysregulation, leading to a hyperinflammatory state often reported in obese patients [29].

nAChRs are present in the lung epithelium. The non-neuronal cholinergic system contributes to the regulation of cell functions such as cell-cell interaction, apoptosis, and proliferation and it is well established that human bronchial epithelial cells contain nAChRs. The airway epithelium expresses $\square 3, \square 4, \square 5, \square 7, \square 9, \square 2$, and $\square 4$-nAChRs subunits [34-37] and their contribution has been discussed in the framework of airway epithelial basal cell proliferation-differentiation and their alteration in lung cancers [38]. These nAChRs are mentioned here as possible targets of Covid-19 infection of the lung, which would take place concomitantly with, and/or as a consequence of, the neuroinfection. Additionally, nAChRs are involved in lung perfusion regulation, which seems to be disrupted in the atypical acute respiratory distress syndrome reported in Covid-19 patients [3].

A potential protective effect of smoking and of nicotine on SARS-CoV-2 infection has been noted. Until recently [39], no firm conclusions could be drawn from studies evaluating the rates of current smokers in Covid-19. All these studies [40-48], although reporting low rates of current smokers, ranging from $1.4 \%$ to $12.5 \%$, did not take into account the main potential confounders of smoking including age and sex. In the study that two of us are reporting [1], the rates of current smoking remain below $5 \%$ even when main confounders for tobacco consumption, i.e. age and sex, in- or outpatient 
status, were considered. Compared to the French general population, the Covid-19 population exhibited a significantly weaker current daily smoker rate by $80.3 \%$ for outpatients and by $75.4 \%$ for inpatients. Thus, current smoking status appears to be a protective factor against the infection by SARS-CoV-2. Although the chemistry of tobacco smoke is complex, these data are consistent with the hypothesis that its protective role takes place through direct action on various types of nAChRs expressed in neurons, immune cells (including macrophages), cardiac tissue, lungs, and blood vessels.

Mechanisms eng aged in Covid-19 as nAChR disease might be tentatively suggested. There is structural evidence supporting the hypothesis that SARS-CoV-2 virus is a nicotinic agent. The recently reported X-ray structure of the RABV glycoprotein (G) ectodomain [49] shows that the region corresponding to the neurotoxin-like peptide is exposed at the G surface, in agreement with the fact that this region is part of the major antigenic region II of RABV [50]. The recently published cryo-EM structure of the trimeric SARS-CoV-2 spike (S) protein $[51,52]$ revealed an insertion with respect to that of SARS-CoV-1, in a loop that is disordered in the reported structure, and which has a polybasic sequence that corresponds to a furin site. Importantly, this exposed loop of the SARS-CoV-2 S protein also contains a motif that is homologous to that of snake neurotoxins and to the RABV neurotoxin-like region (Figure). This observation supports the hypothesis that SARS-CoV-2 virus itself is a nAChR blocker.

COBRA TOXIN RABV G (CVS) RABV G (ERA) RABV G (MOd. ERA) BUNGAROTOXIN

AA SARS-COV-2 S

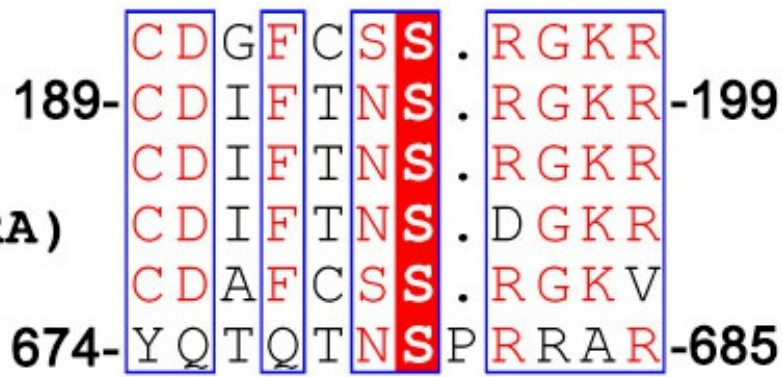

Figure: The neurotoxin motifs. Amino acid sequence alignment of the motifs found in toxins from snakes of the Ophiophagus (cobra) and Bungarus genera, in G from three RABV strains and in S from SARS-CoV2

Nicotine may be suggested as a potential preventive agent against Covid-19 infection. Both the epidemiological/clinical evidence and the in silico findings may suggest that Covid-19 infection is a nAChR disease that could be prevented and may be controlled by 
nicotine. Nicotine would then sterically or allosterically compete with the SARS-CoV-2 binding to the nAChR. This legitimates the use of nicotine as a protective agent against SARS-CoV-2 infection and the subsequent deficits it causes in the CNS. Thus, in order to prevent the infection and the retro-propagation of the virus through the CNS, we plan a therapeutic assay ag ainst Covid-19 with nicotine (and other nicotinic agents) patches or other delivery methods (like sniffing/chewing) in hospitalized patients and in the general population

In conclusion, we propose, and try to justify, the hypothesis that nAChRs play a critical role in the pathophysiology of SARS-CoV-2 infection and as a consequence propose nicotine and nicotinic orthosteric and/or allosteric agents as a possible therapy for SARSCoV-2 infection. Interestingly, ivermectin, which has been recently shown to inhibit the replication of SARS-CoV-2 in cells in vitro [53], is a positive allosteric modulator of a7 nAChR [54]. The nicotinic hypothesis might be further challenged by additional clinical studies and by experimental observations determining whether SARS-CoV-2 physically interacts with the nAChR in vitro, for instance by electrophysiological recordings, high resolution EM and by animal model studies. Further work should also specify the still enigmatic relationships between ACE2 and nAChRs in the nervous system. One should not forget that nicotine is a drug of abuse (53) responsible for smoking addiction. Smoking has severe pathological consequences and remains a serious danger for health. Yet under controlled settings, Nicotinic agents could provide an efficient treatment for an acute infection such as Covid-19.

\section{Acknowledgments}

We would like to specially thank Pr Serge Haroche for establishing the contact between JPC and ZA. We thank Dr. Pablo Guardado Calvo (Institut Pasteur, Paris) for the amino acid sequence analysis of the neurotoxin motif, Pr Florence Tubach for fruitful discussions, Pr.Gérard Orth for valuable support and discussions, Pr Daniel Louvard and Pr Henri Korn for encouragements. JPC acknowledge useful exchanges with Dr Abdul Mohammed and Dr Kister Kristenssen at early stages of the reflection and the Pasteur Institute shared discussions network organized by the Neuroscience Department and its former Chairman Pr PM Lledo. We thank Dr Kurt Sailor for carefully editing the text. COMPETING FINANCIAL INTERESTS

The authors declare no competing financial interests.

\section{REFERENCES}


1. Miyara M, T ubach F, Martinez V, Panzini-Morelot C, Pernet J, Haroche J, Morawiec E Gorochov G, Caumes E, Hausfater P, Combes A, Similowski T, Amoura Z. Low incidence of daily active smokers in patients with symptomatic COVID19. Qeios 2020. https://doi.org/10.32388/WPP19W.3

2. Lauer SA, Grantz KH, Bi Q, Jones FK, Zheng Q, Meredith HR, Azman AS, Reich NG, Lessler J. The Incubation Period of Coronavirus Disease 2019 (COVID-19) From Publicly Reported Confirmed Cases: Estimation and Application. Ann Intern Med 2020.

3. Gattinoni L, Coppola S, Cressoni M, Busana M, Chiumello D. Covid-19 Does Not Lead to a "Typical" Acute Respiratory Distress Syndrome. Am J Respir Crit Care Med 2020.

4. Hoffmann M, Kleine-Weber H, Schroeder S, Kruger N, Herrler T, Erichsen S, Schiergens TS, Herrler G, Wu NH, Nitsche A, Muller MA, Drosten C, Pohlmann S. SARSCoV-2 Cell Entry Depends on ACE2 and TMPRSS2 and Is Blocked by a Clinically Proven Protease Inhibitor. Cell 2020.

5. Lan J, Ge J, Yu J, Shan S, Zhou H, Fan S, Zhang Q, Shi X, Wang Q, Zhang L, Wang X. Structure of the SARS-CoV-2 spike receptor-binding domain bound to the ACE2 receptor. Nature 2020.

6. Yan R, Zhang Y, Li Y, Xia L, Guo Y, Zhou Q. Structural basis for the recognition of SARS-CoV-2 by full-length human ACE2. Science 2020; 367:1444-8.

7. Hikmet F, Méar $L$, Uhlén M, Lindskog C. The protein expression profile of ACE2 in human tissues. bioRxiv 2020:2020.03.31.016048.

8. Xia H, Lazartigues E. Ang iotensin-converting enzyme 2: central regulator for cardiovascular function. Curr Hypertens Rep 2010; 12:170-5.

9. Oakes JM, Fuchs RM, Gardner JD, Lazartigues E, Yue X. Nicotine and the reninangiotensin system. Am J Physiol Regul Integr Comp Physiol 2018; 315:R895-R906.

10. Steardo L, Steardo L, Jr., Zorec R, Verkhratsky A. Neuroinfection may potentially contribute to pathophysiology and clinical manifestations of COVID-19. Acta Physiol (Oxf) 2020:e13473.

11. Li YC, Bai WZ, Hashikawa T. The neuroinvasive potential of SARS-CoV2 may play a role in the respiratory failure of COVID-19 patients. J Med Virol 2020.

12. Baig AM, Khaleeq A, Ali U, Syeda H. Evidence of the COVID-19 Virus Targeting the CNS: T issue Distribution, Host-Virus Interaction, and Proposed Neurotropic Mechanisms. ACS Chem Neurosci 2020; 11:995-8.

13. Gane SB, Kelly C, Hopkins C. Isolated sudden onset anosmia in COVID-19 infection. A novel syndrome? Rhinology 2020.

14. Ling Mao MW, Shanghai Chen, Quanwei He, Jiang Chang, Candong Hong, Yifan 
Zhou, David Wang, Yanan Li, Huijuan Jin, Bo Hu. Neurological Manifestations of Hospitalized Patients with COVID-19 in Wuhan, China: a retrospective case series study. medRxiv 2020.

15. Wang D, Hu B, Hu C, Zhu F, Liu X, Zhang J, Wang B, Xiang H, Cheng Z, Xiong Y, Zhao Y, Li Y, Wang X, Peng Z. Clinical Characteristics of 138 Hospitalized Patients With 2019 Novel Coronavirus-Infected Pneumonia in Wuhan, China. JAMA 2020.

16. Mohammed AH, Norrby E, Kristensson K. Viruses and behavioural changes: a review of clinical and experimental findings. Rev Neurosci 1993; 4:267-86.

17. Tesoriero C, Codita A, Zhang MD, Cherninsky A, Karlsson H, Grassi-Zucconi G, Bertini G, Harkany T, Ljung berg K, Liljestrom P, Hokfelt TG, Bentivog lio M, Kristensson K. H1N1 influenza virus induces narcolepsy-like sleep disruption and targets sleep-wake regulatory neurons in mice. Proc Natl Acad Sci U S A 2016; 113:E368-77.

18. Kristensson K. Microbes' roadmap to neurons. Nat Rev Neurosci 2011; 12:34557.

19. MacGibeny MA, Koyuncu OO, Wirblich C, Schnell MJ, Enquist LW. Retrograde axonal transport of rabies virus is unaffected by interferon treatment but blocked by emetine locally in axons. PLoS Pathog 2018; 14:e1007188.

20. Hueffer K, Khatri S, Rideout S, Harris MB, Papke RL, Stokes C, Schulte MK. Rabies virus modifies host behaviour through a snake-toxin like region of its glycoprotein that inhibits neurotransmitter receptors in the CNS. Sci Rep 2017; 7:12818.

21. Lentz TL, Burrage T G, Smith AL, Crick J, T ignor GH. Is the acetylcholine receptor a rabies virus receptor? Science 1982; 215:182-4.

22. Lentz TL, Hawrot E, Wilson PT. Synthetic peptides corresponding to sequences of snake venom neurotoxins and rabies virus glycoprotein bind to the nicotinic acetylcholine receptor. Proteins 1987; 2:298-307.

23. Changeux JP, Kasai M, Lee CY. Use of a snake venom toxin to characterize the cholinergic receptor protein. Proc Natl Acad Sci U S A 1970; 67:1241-7.

24. Lee CY, Chang CC. Modes of actions of purified toxins from elapid venoms on neuromuscular transmission. Mem Inst Butantan 1966; 33:555-72.

25. Corringer PJ, Poitevin F, Prevost MS, Sauguet L, Delarue M, Changeux JP. Structure and pharmacology of pentameric receptor channels: from bacteria to brain. Structure 2012; 20:941-56.

26. Cecchini M, Changeux JP. The nicotinic acetylcholine receptor and its prokaryotic homologues: Structure, conformational transitions \& allosteric modulation. Neuropharmacology 2015; 96:137-49.

27. Gotti C, Clementi F. Neuronal nicotinic receptors: from structure to pathology. Prog Neurobiol 2004; 74:363-96. 
28. Wang H, Yu M, Ochani M, Amella CA, Tanovic M, Susarla S, Li JH, Yang H, Ulloa L, Al-Abed Y, Czura CJ, Tracey KJ. Nicotinic acetylcholine receptor alpha7 subunit is an essential regulator of inflammation. Nature 2003; 421:384-8.

29. Pavlov VA, Tracey KJ. The vagus nerve and the inflammatory reflex--linking immunity and metabolism. Nat Rev Endocrinol 2012; 8:743-54.

30. Chen G, Wu D, Guo W, Cao Y, Huang D, Wang H, Wang T, Zhang X, Chen H, Yu H, Zhang M, Wu S, Song J, Chen T, Han M, Li S, Luo X, Zhao J, Ning Q. Clinical and immunologic features in severe and moderate Coronavirus Disease 2019. J Clin Invest 2020.

31. Kooijman S, Meurs I, van der Stoep M, Habets KL, Lammers B, Berbee JF, Havekes LM, van Eck M, Romijn JA, Korporaal SJ, Rensen PC. Hematopoietic alpha7 nicotinic acetylcholine receptor deficiency increases inflammation and platelet activation status, but does not aggravate atherosclerosis. J Thromb Haemost 2015; 13:126-35.

32. van Westerloo DJ, Giebelen IA, Florquin S, Bruno MJ, Larosa GJ, Ulloa L, Tracey KJ, van der Poll T. The vagus nerve and nicotinic receptors modulate experimental pancreatitis severity in mice. Gastroenterology 2006; 130:1822-30.

33. van Westerloo DJ, Giebelen IA, Florquin S, Daalhuisen J, Bruno MJ, de Vos AF, Tracey $\mathrm{KJ}$, van der Poll T. The cholinergic anti-inflammatory pathway regulates the host response during septic peritonitis. J Infect Dis 2005; 191:2138-48.

34. Zia S, Ndoye A, Nguyen VT, Grando SA. Nicotine enhances expression of the alpha 3, alpha 4, alpha 5, and alpha 7 nicotinic receptors modulating calcium metabolism and regulating adhesion and motility of respiratory epithelial cells. Res Commun Mol Pathol Pharmacol 1997; 97:243-62.

35. Maus AD, Pereira EF, Karachunski PI, Horton RM, Navaneetham D, Macklin K, Cortes WS, Albuquerque EX, Conti-Fine BM. Human and rodent bronchial epithelial cells express functional nicotinic acetylcholine receptors. Mol Pharmacol 1998; 54:779-88. 36. Carlisle DL, Hopkins TM, Gaither-Davis A, Silhanek MJ, Luketich JD, Christie NA, Siegfried JM. Nicotine signals through muscle-type and neuronal nicotinic acetylcholine receptors in both human bronchial epithelial cells and airway fibroblasts. Respir Res 2004; $5: 27$.

37. Maouche K, Polette M, Jolly T, Medjber K, Cloez-Tayarani I, Changeux JP, Burlet H, Terryn C, Coraux C, Zahm JM, Birembaut P, T ournier JM. \{alpha\}7 nicotinic acetylcholine receptor regulates airway epithelium differentiation by controlling basal cell proliferation. Am J Pathol 2009; 175:1868-82.

38. Cheng WL, Chen KY, Lee KY, Feng PH, Wu SM. Nicotinic-nAChR signaling mediates drug resistance in lung cancer. J Cancer 2020; 11:1125-40.

39. Lippi G, Henry BM. Active smoking is not associated with severity of coronavirus 
disease 2019 (COVID-19). Eur J Intern Med 2020.

40. Guan WJ, Ni ZY, Hu Y, Liang WH, Ou CQ, He JX, Liu L, Shan H, Lei CL, Hui DSC, Du B, Li LJ, Zeng G, Yuen KY, Chen RC, T ang CL, Wang T, Chen PY, Xiang J, Li SY, Wang JL, Liang ZJ, Peng YX, Wei L, Liu Y, Hu YH, Peng P, Wang JM, Liu JY, Chen Z, Li G, Zheng ZJ, Qiu SQ, Luo J, Ye CJ, Zhu SY, Zhong NS. Clinical Characteristics of Coronavirus Disease 2019 in China. N EnglJ Med 2020.

41. Huang C, Wang Y, Li X, Ren L, Zhao J, Hu Y, Zhang L, Fan G, Xu J, Gu X, Cheng Z, Yu T, Xia J, Wei Y, Wu W, Xie X, Yin W, Li H, Liu M, Xiao Y, Gao H, Guo L, Xie J, Wang G, Jiang R, Gao Z, Jin Q, Wang J, Cao B. Clinical features of patients infected with 2019 novel coronavirus in Wuhan, China. Lancet 2020; 395:497-506.

42. Liu J, Liu Ouyang PG, Hai sheng Wu, Peng Fu, Yu liang Chen, Dan Yang, Xiao yu Han, Yu kun Cao, Osamah Alwalid, Juan Tao, Shu yi Peng, He shui Shi, Fan Yang, Chuan sheng Zheng. Epidemiological, Clinical Characteristics and Outcome of Medical Staff Infected with COVID-19 in Wuhan, China: A Retrospective Case Series Analysis. medRxiv 2020.

43. Liu W, T ao ZW, Lei W, Ming-Li Y, Kui L, Ling Z, Shuang W, Yan D, Jing L, Liu HG, Ming Y, Yi H. Analysis of factors associated with disease outcomes in hospitalized patients with 2019 novel coronavirus disease. Chin Med J (Engl) 2020.

44. Mo P, Xing Y, Xiao Y, Deng L, Zhao Q, Wang H, Xiong Y, Cheng Z, Gao S, Liang K, Luo M, Chen T, Song S, Ma Z, Chen X, Zheng R, Cao Q, Wang F, Zhang Y. Clinical characteristics of refractory COVID-19 pneumonia in Wuhan, China. Clin Infect Dis 2020. 45. Wan S, Xiang Y, Fang W, Zheng Y, Li B, Hu Y, Lang C, Huang D, Sun Q, Xiong Y, Huang X, Lv J, Luo Y, Shen L, Yang H, Huang G, Yang R. Clinical features and treatment of COVID-19 patients in northeast Chongqing. J Med Virol 2020.

46. Yang X, Yu Y, Xu J, Shu H, Xia J, Liu H, Wu Y, Zhang L, Yu Z, Fang M, Yu T, Wang Y, Pan S, Zou X, Yuan S, Shang Y. Clinical course and outcomes of critically ill patients with SARS-CoV-2 pneumonia in Wuhan, China: a single-centered, retrospective, observational study. Lancet Respir Med 2020.

47. Zhang ل, Dong X, Cao YY, Yuan YD, Yang YB, Yan YQ, Akdis CA, Gao YD. Clinical characteristics of 140 patients infected with SARS-CoV-2 in Wuhan, China. Allergy 2020.

48. Zhou F, Yu T, Du R, Fan G, Liu Y, Liu Z, Xiang J, Wang Y, Song B, Gu X, Guan L, Wei Y, Li H, Wu X, Xu J, Tu S, Zhang Y, Chen H, Cao B. Clinical course and risk factors for mortality of adult inpatients with COVID-19 in Wuhan, China: a retrospective cohort study. Lancet 2020; 395:1054-62.

49. Yang F, Lin S, Ye F, Yang J, Qi J, Chen Z, Lin X, Wang J, Yue D, Cheng Y, Chen H, You Y, Zhang Z, Yang Y, Yang M, Sun H, Li Y, Cao Y, Yang S, Wei Y, Gao GF, Lu G. Structural Analysis of Rabies Virus Glycoprotein Reveals pH-Dependent Conformational Changes 
and Interactions with a Neutralizing Antibody. Cell Host Microbe 2020; 27:441-53 e7.

50. Bakker AB, Marissen WE, Kramer RA, Rice AB, Weldon WC, Niezgoda M, Hanlon CA, Thijsse S, Backus HH, de Kruif J, Dietzschold B, Rupprecht CE, Goudsmit J. Novel human monoclonal antibody combination effectively neutralizing natural rabies virus variants and individual in vitro escape mutants. JVirol 2005; 79:9062-8.

51. Wrapp D, Wang N, Corbett KS, Goldsmith JA, Hsieh CL, Abiona O, Graham BS, McLellan JS. Cryo-EM structure of the 2019-nCoV spike in the prefusion conformation. Science 2020; 367:1260-3.

52. Walls AC, Park YJ, Tortorici MA, Wall A, McGuire AT, Veesler D. Structure, Function, and Antig enicity of the SARS-CoV-2 Spike Glycoprotein. Cell 2020.

53. Caly L, Druce JD, Catton MG, Jans DA, Wagstaff KM. The FDA-approved Drug Ivermectin inhibits the replication of SARS-CoV-2 in vitro. Antiviral Res 2020:104787. 54. Krause RM, Buisson B, Bertrand S, Corringer PJ, Galzi JL, Changeux JP, Bertrand D. Ivermectin: a positive allosteric effector of the alpha7 neuronal nicotinic acetylcholine receptor. Mol Pharmacol 1998; 53:283-94.

\section{Authors:}

Jean-Pierre Changeux 1 *\# and Zahir Amoura 2, 3 * Felix A. Rey4 and Makoto Miyara 2, 5

1.Institut Pasteur CNRS UMR 3571 Department of Neuroscience and Collège de France, Paris France, 2.Sorbonne Université, Inserm UMRS, Centre d'Immunologie et des Maladies Infectieuses (CIMI-Paris), 3.Assistance Publique-Hôpitaux de Paris, Groupement Hospitalier Pitié-Salpêtrière, Service de Médecine Interne 2, Maladies auto-immune et systémiques Institut E3M, 4. Institut Pasteur, Structural Virology Unit, Department of Virology, CNRS UMR 3569, Institut Pasteur Paris France, 5. Assistance Publique-Hôpitaux de Paris, Groupement Hospitalier Pitié-Salpêtrière, Département d'Immunologie, Paris, France. * equal first authors.

\# to whom correspondence should addressed: changeux@noos.fr 